\title{
Protocolo de asepsia y utilización adecuada de recursos en hemodiálisis
}

Cruz Esteban Guajardo ** - $\mathbf{M}^{\mathrm{a}}$ José Rubio Montuenga * - $\mathbf{M}^{\mathrm{a}}$ Jesús Forcén Casado * - $\mathbf{M}^{\mathrm{a}}$ Pilar Aranda Fernández * - Rosa Isabel Lafuente Millán * - Vanesa Villafaina Guzmán *

\section{Supervisora}

* Diplomada en Enfermería. Hospital Ernest Lluch. Calatayud (Zaragoza)

\section{Sra. Directora:}

El término "calidad" cada vez nos resulta más familiar a los profesionales de la salud, ya que en mayor o menor medida nos vemos interesados e implicados en Programas de Calidad, Gestión de Calidad o Controles de Calidad.

En la actualidad disponemos, por lo general, de todos los recursos materiales y humanos necesarios para llevar a cabo nuestra práctica asistencial, pero no siempre cumplimos con las normas de asepsia para evitar la transmisión de infecciones, ya sea por desconocimiento, porque no nos parecen lo suficientemente importantes, a veces, para ir más deprisa 0 porque con el tiempo nos vamos "relajando".

En nuestra Unidad se aplican las Medidas Universales para prevenir la transmisión de Infecciones recogidas en la Guía sobre Enfermedades Víricas en Hemodiálisis, editada por la Sociedad Española de Nefrología (SEN). Se siguen las recomendaciones

\footnotetext{
Correspondencia:

$\mathrm{M}^{\mathrm{a}}$ José Rubio Montuenga

Unidad de Hemodiálisis

Hospital "Ernest Lluch"

Ctra. Sagunto-Burgos, Km 254

50300 Calatayud (Zaragoza)

mjrubio@salud.aragon.es
}

generales, las precauciones que deben aplicar tanto el personal como los pacientes, los criterios de uso y limpieza de las salas, monitores, utensilios y material, así como las normas en unidades de agudos, traslados y pacientes de vacaciones, además de la formación continuada del personal.

Pero a veces el personal de Enfermería de nuestra Unidad nos planteábamos las siguientes preguntas: ¿hago un buen uso de los recursos a mi alcance?, ¿protejo de una forma adecuada al paciente?, ¿me protejo yo? Por este motivo nos propusimos conseguir como puntos de mejora la utilización adecuada de los recursos a nuestro alcance, tanto organizativos como materiales, para proteger al paciente y al personal del contagio de posibles infecciones.

Para esto nos planteamos los siguientes objetivos:

- Elaborar un protocolo de asepsia y prevención de infecciones durante la sesión de hemodiálisis.

- Comprobar el cumplimiento del protocolo al cabo de un año de su implantación.

Para ello el equipo de Enfermería de hemodiálisis formado por 5 enfermeras y 1 auxiliar de enfermería realizamos un total de seis reuniones, la primera de las cuales nos sirvió para leer y repasar las Medidas Universales para prevenir la Transmisión de Infecciones de la SEN, revisadas en octubre de 2003. 
En la siguiente reunión realizamos una "tormenta de ideas" en la que fuimos anotando todas las actuaciones que durante la sesión de hemodiálisis ponían en riesgo la pérdida de asepsia, la protección del paciente o la nuestra, al mismo tiempo íbamos aportando soluciones, estableciendo qué puntos de mejora queríamos conseguir.

Elegimos esta herramienta porque queríamos obtener aportaciones de todos los miembros del grupo en un ambiente libre de crítica que facilitara expresar las ideas de forma creativa y sin restricciones.

Posteriormente, una vez recogidos los datos, creímos importante realizar un Protocolo de Asepsia en la sesión de Hemodiálisis, el cual se estructuró en tres apartados:

- Medidas protectoras a utilizar por el personal

- Medidas preventivas por/para el paciente

- Acciones potencialmente contaminantes

Al cabo de un año de tener establecido el Protocolo de Asepsia en la Unidad nos propusimos conocer el cumplimiento del mismo a través de una encuesta que ha sido contestada por la totalidad de las enfermeras y que consta de 14 preguntas. Las posibles contestaciones son:

- SIEMPRE, que se corresponde a la forma correcta de actuar

- A VECES, cuando en algunas ocasiones se actúa correctamente y en otras no

- NUNCA, se corresponde a la forma incorrecta de actuar

Los resultados obtenidos a cada una de las 14 preguntas son los siguientes:

\section{Medidas protectoras a utilizar por el personal}

Pregunta 1. Desecho el material punzante inmediatamente después de su uso, no lo dejo encima del monitor ni encima del campo estéril ni encapucho agujas.

- SIEMPRE: $20 \%$

- A VECES: $40 \%$

- NUNCA: $40 \%$
Pregunta 2. Utilizo vestimenta adecuada (guantes, bata, mascarilla, gafas) en caso de pacientes con serología positiva a hepatitis.

- SIEMPRE: $20 \%$

- A VECES: $60 \%$

- NUNCA: $20 \%$

\section{Medidas preventivas por/para el paciente}

Pregunta 3. Me lavo las manos antes y después de conectar a cada paciente.

- SIEMPRE: $0 \%$

- A VECES: $80 \%$

- NUNCA: $20 \%$

Pregunta 4. Uso guantes estériles para la conexión y comienzo de la diálisis.

Pregunta 5. Uso guantes no estériles para la desconexión y para la manipulación de fluidos orgánicos.

Pregunta 6. Sigo el protocolo específico para la manipulación de catéteres en hemodiálisis. Mantengo la esterilidad durante el proceso de conexión, desconexión, cura del punto de inserción y al comprobar permeabilidad.

Los resultados de las preguntas 4,5 y 6 son:

- SIEMPRE: $100 \%$

Pregunta 7. Limpio el monitor con solución desinfectante cuando se ha manchado de sangre tras la conexión o recolocación de agujas.

Pregunta 8. Antes de la desconexión preparo todo lo necesario (tiritas, esparadrapo, gasas, etc.) para curar los puntos de punción.

Los resultados de las preguntas 7 y 8 son:

- A VECES: $100 \%$

\section{Acciones potencialmente contaminantes}

Pregunta 9. No llevo material de un paciente a otro (gasas, jeringas, pinzas, etc).

- SIEMPRE: $100 \%$ 
Pregunta 10. No toco el monitor cuando suena una alarma con los guantes utilizados para otro paciente.

Pregunta 11. No toco utensilios comunes a todos los pacientes con los guantes ya utilizados como esparadrapo, botes de H202, povidona yodada.

Pregunta 13. No realizo gestos que puedan contaminar material, (líneas en contacto con el pelo o el suelo, chupar el bolígrafo, tocarme las gafas con guantes manchados o tocarme el pelo con el kocher).

Los resultados de las preguntas 10, 11 y 13 son:

- SIEMPRE: $80 \%$

- A VECES: $20 \%$

- NUNCA: $0 \%$

Pregunta 12. Evito tocar con guantes objetos que posteriormente pueden ser tocados sin guantes (teléfono, bolígrafo, gráficas.)

Pregunta 14. Tengo especial cuidado en no contaminar superficies que luego van a ser tocadas sin guantes (tapones de garrafas de concentrado ácido, pipetas, etc.).

Los resultados de las preguntas 12 y 14 son:

- SIEMPRE: $40 \%$

- A VECES: $60 \%$

- NUNCA: $0 \%$

Ante estos resultados pensamos que el trabajo en equipo nos ha permitido conocer los motivos por los que se perdían las normas de asepsia y encontrar soluciones, las cuales son conocidas y compartidas por todo el grupo y el Protocolo de Asepsia durante la Sesión de Hemodiálisis nos ha servido para unificar nuestras actuaciones y organizar mejor nuestro trabajo, en definitiva para mejorar la calidad del mismo.

Por otra parte, los resultados obtenidos en las encuestas demuestran que debemos realizar un mejor seguimiento del protocolo sobre todo en lo referente a medidas protectoras a utilizar por el personal, al lavado de manos antes y después de conectar a cada paciente y a evitar tocar con guantes objetos y superficies que posteriormente pueden ser tocadas sin guantes. Creemos conveniente realizar controles de actuación periódicamente que revisen el cumplimiento de las Medidas de Precaución Universales a aplicar en las Unidades de Hemodiálisis para evitar infecciones y mantener unas Normas de Calidad. Esta revisión periódica nos facilita no caer en la rutina, realizar una buena práctica utilizando bien los recursos materiales y humanos y respetar y cuidar el medio ambiente.

\section{Agradecimientos}

Agradecemos la colaboración del médico preventivista José Ignacio García y de los nefrólogos: Elena Castillón y Ángel Blasco por su ayuda en la realización de éste trabajo.

\section{Bibliografía}

1. Comisión de expertos de la Sociedad Española de Nefrología (S.E.N.) para la creación de unas Guías sobre enfermedades víricas en Hemodiálisis. Última modificación 10-0ctubre-2003; 5-6, 17 23.

2. Programa de Calidad (sede Web). Buenos Aires: Asociación Regional de Diálisis y Trasplantes Renales de Capital Federal y Provincia de Buenos Aires. 2006 (acceso 29 de marzo de 2007). De Lavorato. C. Programa de calidad en diálisis. Disponible en: http://www.renal.org.ar/calidad/calidad.htm

3. Unidad de Calidad Asistencial. Curso de Gestión de Calidad Asistencial. Noviembre-2005; 3-12. 